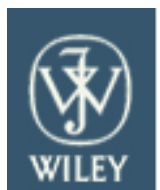

Computer Applications in Engineering Education

\title{
THE ROLE OF OSC-BASED PROJECTS IN MEETING NEW CHALLENGES OF EDUCATION-CONCEPT AND EXEMPLIFICATION
}

\begin{tabular}{|r|l|}
\hline Journal: & Computer Applications in Engineering Education \\
\hline Manuscript ID: & CAE-10-121.R1 \\
\hline Wiley - Manuscript type: & Research Article \\
\hline Author: & $\mathrm{n}$ /a \\
\hline Complete List of Authors: & $\begin{array}{l}\text { Ilie-Zudor, Elisabeth; MTA SZTAKI, Research Laboratory on } \\
\text { Engineering \& Management Intelligence } \\
\text { Kemeny, Zsolt; Computer and Automation Research Institute, } \\
\text { Hungarian Academy of Sciences, Engineering \& Management } \\
\text { Intelligence } \\
\text { Szathmari, Marcell; Computer and Automation Research Institute, } \\
\text { Hungarian Academy of Sciences, Engineering \& Management } \\
\text { Intelligence } \\
\text { Monostori, Laszlo; MTA SZTAKI, Research Laboratory on } \\
\text { Engineering \& Management Intelligence }\end{array}$ \\
\hline Keywords: & $\begin{array}{l}\text { technical education, open source, life-long learning, training, } \\
\text { tracking and tracing }\end{array}$ \\
\hline \hline
\end{tabular}

\section{SCHOLARONE Manuscripts}




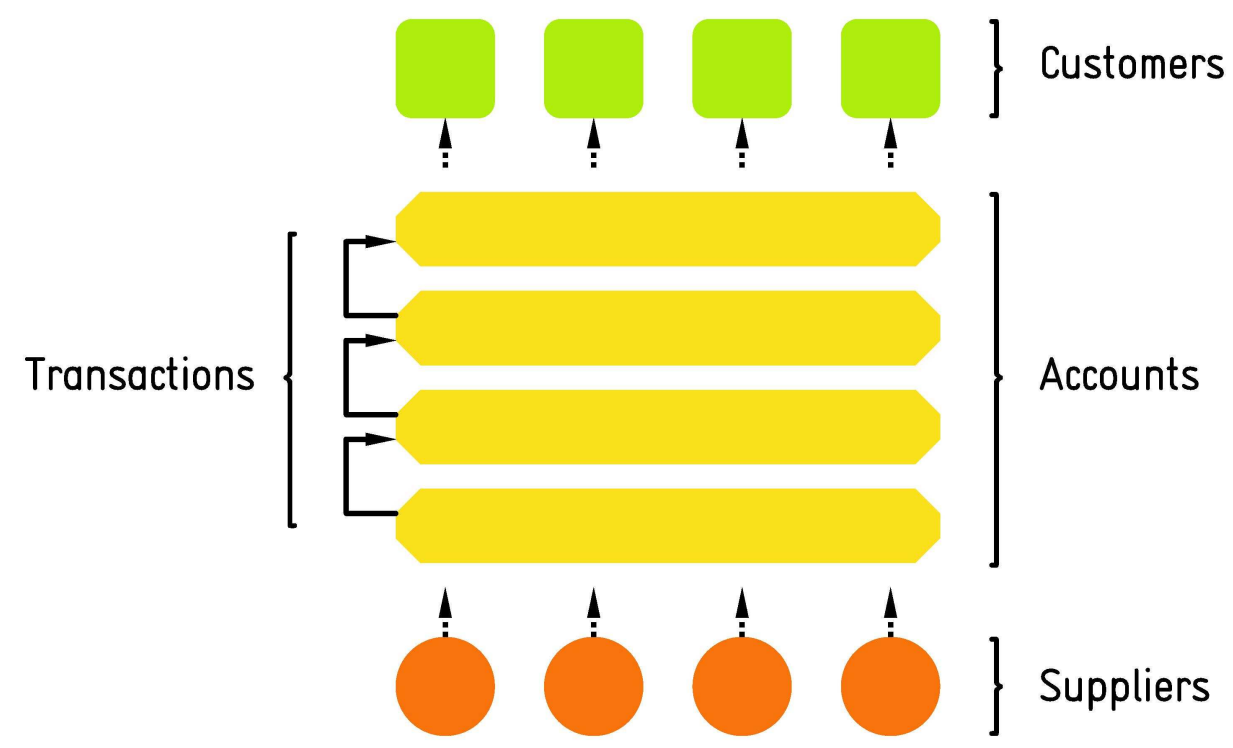

Figure 1: Account-based material management $131 \times 82 \mathrm{~mm}(600 \times 600 \mathrm{DPI})$ 


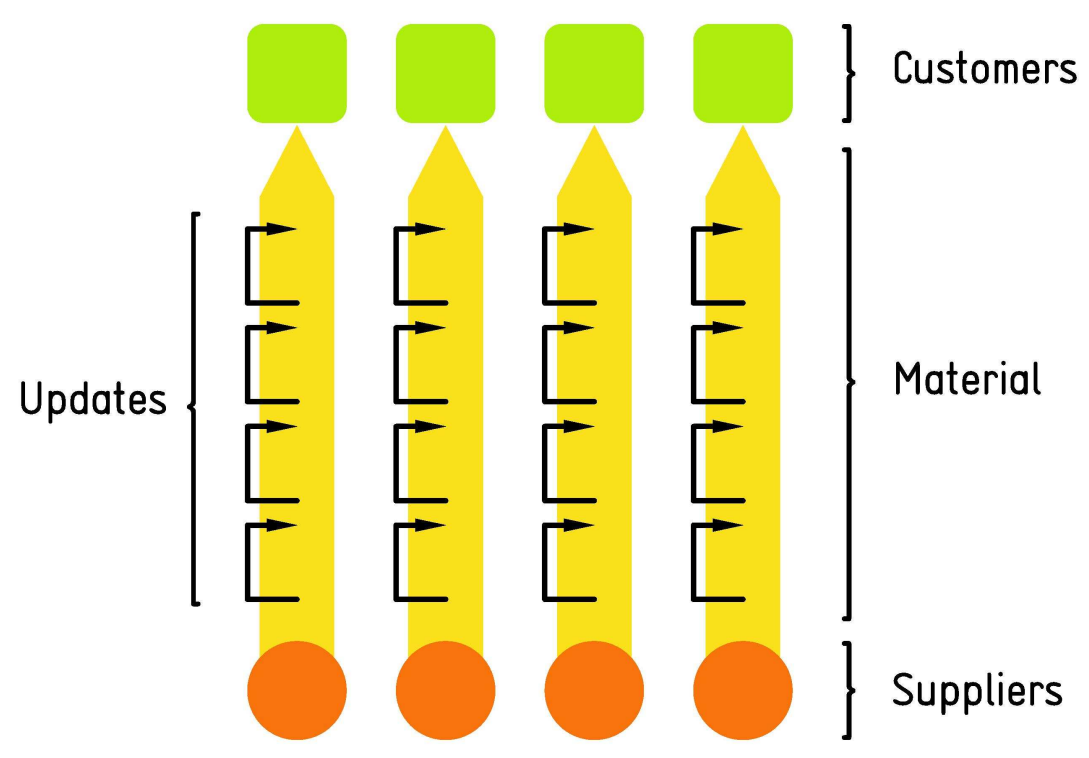

Figure 2 Item-centric material management $131 \times 82 \mathrm{~mm}(600 \times 600 \mathrm{DPI})$ 
a)



b)

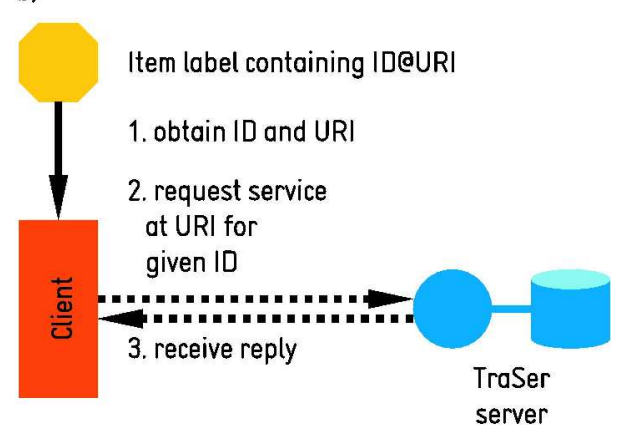

Figure 3: Comparison of lookup-based mapping of unique ID and service access address (a) vs. the ID@URI principle (b) where the access address for services related to the given item can directly be obtained from the unique ID $132 \times 61 \mathrm{~mm}(600 \times 600 \mathrm{DPI})$ 
Figure 4: Access to item-related services in a TraSer network using various methods of unique identification and specialized clients using different interfaces. Freedom in addition of customized clients allows the adaptation and coupling of a TraSer-based solution with other components and systems $154 \times 56 \mathrm{~mm}(600 \times 600 \mathrm{DPI})$ 


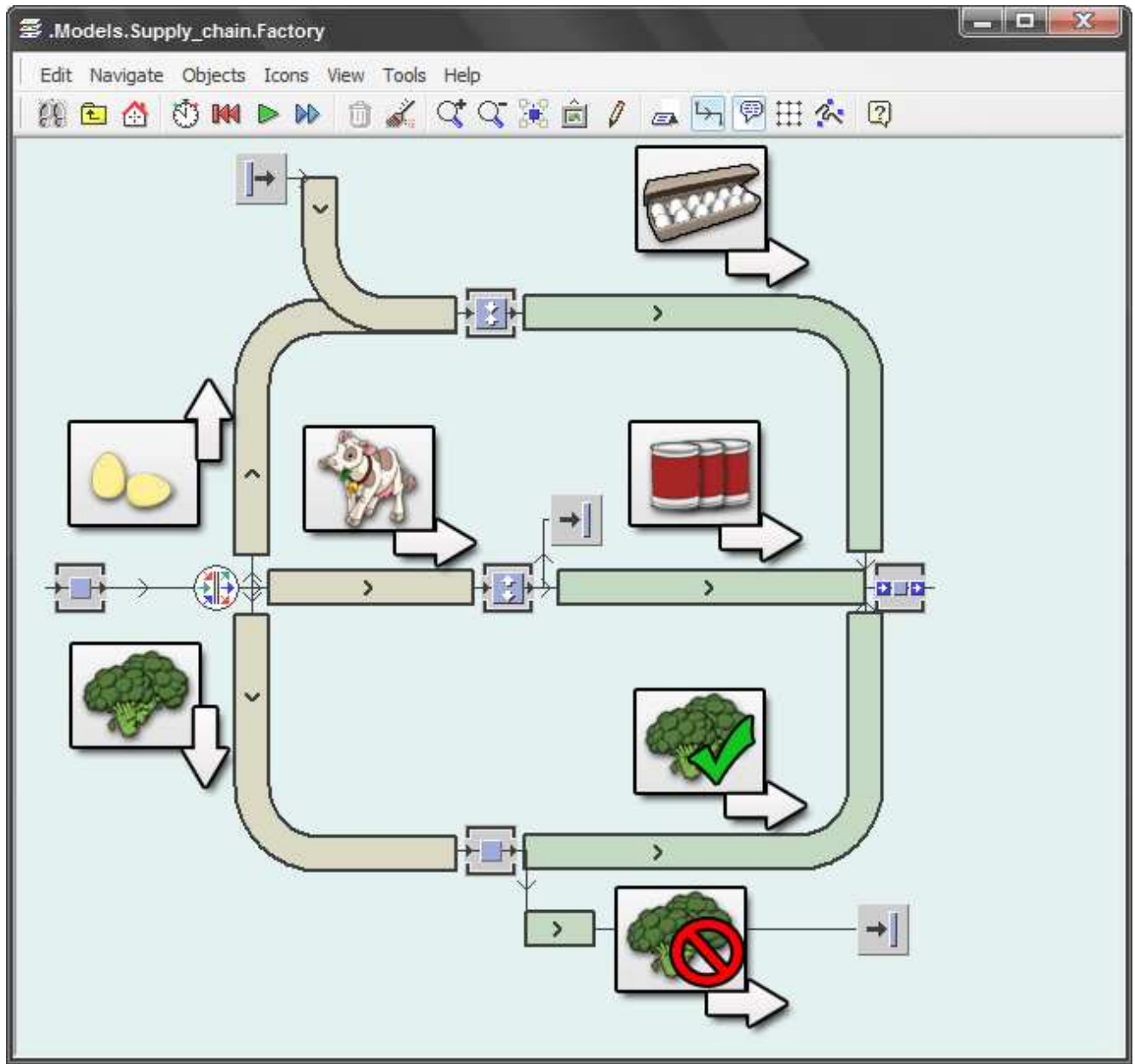

Figure 5: Processes inside a sample food processing plant $174 \times 164 \mathrm{~mm}$ ( $96 \times 96 \mathrm{DPI})$ 


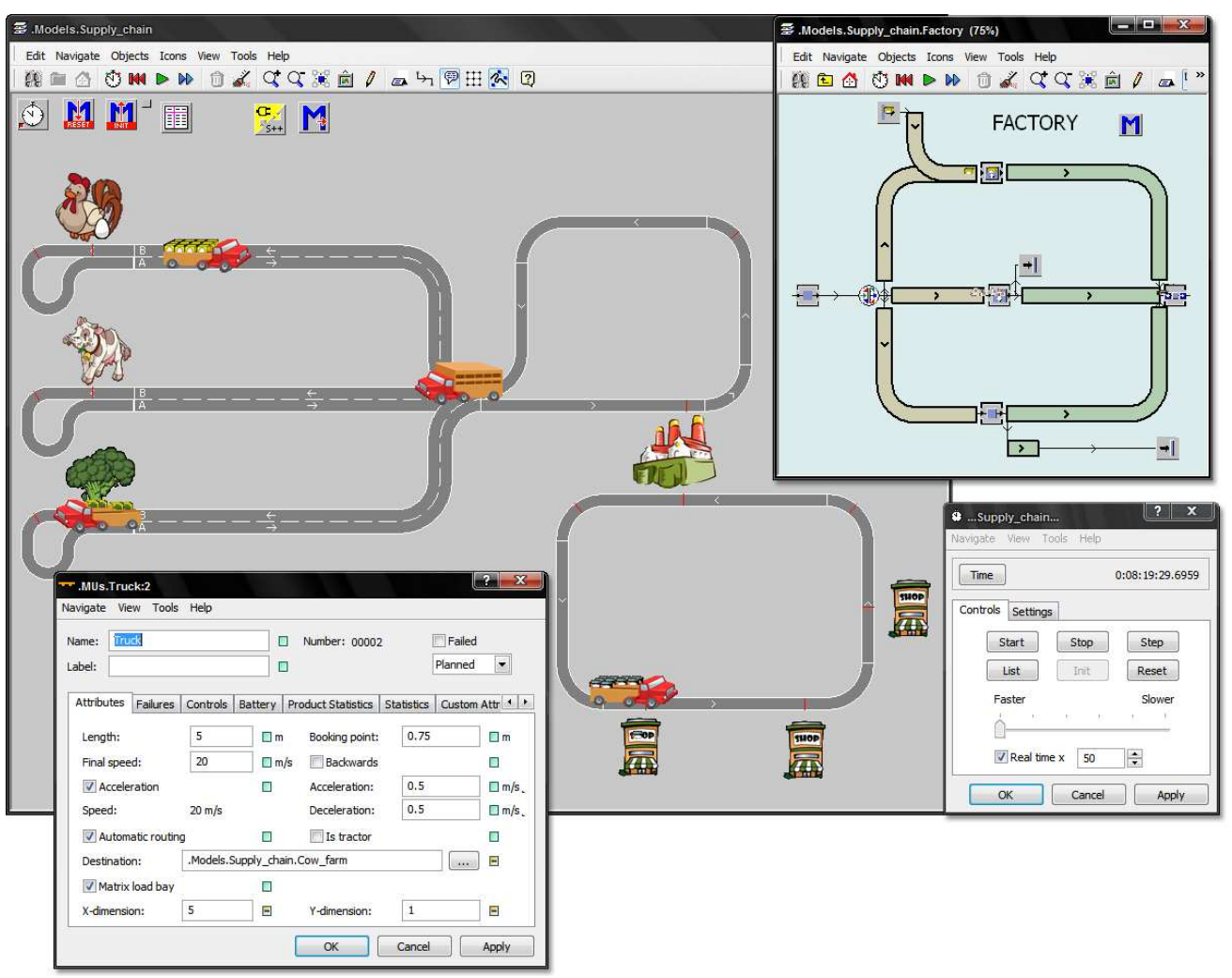

Figure 6: Application of the TraSer platform-tracking in a simplified food supply chain $318 \times 250 \mathrm{~mm}(96 \times 96$ DPI) 


\begin{abstract}
Latest developments in economy and industry have shed light on the growing importance of flexible and practice-oriented skills of industrial employees. Much improvement can be achieved by adapting the current practices of education accordingly, e.g., by emphasizing hands-on experience and preparing learners (both students and employees in extended training) for independent life-long learning strategies. The paper highlights the importance of open-source software in this context. After giving an overview of R\&D projects delivering open-source solutions and existing open-source communities, the example of the TraSer project (an open-source solution platform for track-and-trace applications) is closer examined, with special emphasis on its potential role in education at universities and industrial companies.
\end{abstract}

Keywords: Technical education, training, life-long learning, open source, tracking and tracing

\title{
1. INTRODUCTION
}

At a time when competition and entrepreneurial spirit is increasing, businesses need new innovation models and graduates with stronger knowledge of latest research developments and multi-disciplinary/application-oriented skills.

As laid down by the European Commission in its press document (1), in the context of the current recession the view is emerging more strongly than ever that innovation is a vital driver of sustainable growth and a key component of the response to global and societal challenges. This applies to knowledge acquisition as well, both in school and in the further process of life-long learning. Innovative learning and learning about innovative concepts and developments is greatly facilitated nowadays by the evolution of information and communication technologies. New approaches to knowledge acquisition can and are being taken, such as on-line distance learning (2), (3), collaborative learning (7), (4), supplying novel views (e.g., multimedia material, interactive virtual models) at a given domain ( (8) (9) (10) (11), (5)); customized study schedules and reliable self-assessment (12), (13), webbased educational simulation (6).

It is an emerging trend that international consortia working in EU-funded projects commit themselves to sharing their software developments and related documentation freely accessible in an open-source community (OSC). Knowledge acquisition based on developments of OSC type projects can be of benefit both in the education of college or university students, and in the life-long learning process of employees in industry. There are many advantages of using the OSC projects as means/source of teaching, such as:

- Access to applications, implementation results and information related to the newest technologies and research developments,

- The possibility of implementing or testing latest-development software in laboratories or industrial environments without any acquisition/development costs,

- Gaining knowledge about practical real-life applications through reports on pilot implementations to be found directly on the web-pages of the projects or included in the publications of the consortium,

- Gaining more opportunities of "learning-by-doing" approaches as learners (students or employees in industry) can easily amend an open-source code and try their own concepts in practice (17), (19), 
- Attaining better insight into the inner functioning of the software solution-either by examining scenarios already covered by the materials offered, or by developing new samples-as open-source software allows more than a black-box perspective (20),

- Early exposure of students to industry-relevant problems and perspectives (e.g., application obstacles with small and medium-size enterprises, SMEs), thereby preparing them for efficiently finding solutions in real life, and shaping the views of less prepared employees on the problem and its solutions to the employer's benefit.

Teachers can freely (without any acquisition cost) include modules based on OSC type projects in their courses, helping their pupils to have both knowledge about practical real-life applications and knowledge of new research technologies. Independent learners also can access the resources of the OSC projects for the same benefits.

\section{OSC-BASED PROJECTS}

There is a number of reasons for which consortia may choose to make their results available in an open-source community. Some of these are:

- The targeted user community is in many cases easier to approach,

- The sustainability of the project results is very likely to be enhanced through the provision of results at no development costs (or minimal, in case the users would like custom made interfaces or additional functionalities),

- Issues related to intellectual property rights within the consortium are minimized,

- Interested parties can further develop the project's software outcome even after the end of the original project.

Nowadays, several branches of industry share one property: enterprises or enterprise groups operating in a networked nature, with higher local independence in operations for competitive advantage through agility and flexibility. This, however, still leaves participants with the challenge of recognizing dependencies of network-wide or long-term significance. Handling this is well-served by an open infrastructure which evolves along community-wide changes and demands low total costs of ownership (TCO). This is best served by open-source software, for the following reasons:

- The low initial investment needed for the installation of the solution platform at participating members is a major advantage (especially relevant for SME members with limited resources) and helps preventing participants from sticking to sub-optimal solutions due to a burden of having already spent considerable amounts on purchase and installation;

- With open source, companies can easily be the driver of future development-instead of demand surveys and "black box" software, they can directly interact with developers and fellow users, interchange experience, and shorten lead times between detecting and solving new problems.

Examples of (EU funded) OSC-based projects are given in the table below (Table 1):

\begin{tabular}{|l|l|l|l|l|}
\hline \multicolumn{1}{|c|}{ Project title } & Acronym & \multicolumn{1}{c|}{ Status } & \multicolumn{1}{c|}{ Web-page } & \multicolumn{1}{c|}{ OSC link } \\
\hline $\begin{array}{l}\text { Model-based Adaptive } \\
\text { Product and Process } \\
\text { Engineering }\end{array}$ & MAPPER & completed & $\begin{array}{l}\text { http://mapper. } \\
\text { eu.org/ }\end{array}$ & $\begin{array}{l}\text { CURE: } \\
\text { http://cure.sourceforge.net/ } \\
\text { Concert Chart: } \\
\text { http://sourceforge.net/projects/con } \\
\text { certchat" }\end{array}$ \\
\hline $\begin{array}{l}\text { Towards integrating virtual } \\
\text { reality and optimisation } \\
\text { techniques in a new } \\
\text { generation of Networked } \\
\text { businesses in Warehouse } \\
\text { Management Systems under } \\
\text { constraints. }\end{array}$ & Net-WMS & completed & $\begin{array}{l}\text { http://net- } \\
\text { wms.ercim.org }\end{array}$ & http://choco.sourceforge.net/ \\
\hline $\begin{array}{l}\text { Advanced Sensors and } \\
\text { lightweight Programmable } \\
\text { middleware for Innovative Rfid }\end{array}$ & ASPIRE & $\begin{array}{l}\text { Under } \\
\text { developme } \\
\text { nt (to be }\end{array}$ & $\begin{array}{l}\text { http://www.fp7- } \\
\text { aspire.eu/ }\end{array}$ & $\begin{array}{l}\text { AspireRFID: } \\
\text { http://wiki.aspire.ow2.org/xwiki/bin } \\
\text { /view/Main/WebHome }\end{array}$ \\
\hline
\end{tabular}




\begin{tabular}{|c|c|c|c|c|}
\hline Enterprise applications & & $\begin{array}{l}\text { completed } \\
\text { December } \\
\text { 2010) }\end{array}$ & & \\
\hline $\begin{array}{l}\text { An Interoperability Service } \\
\text { Utility for Collaborative Supply } \\
\text { Chain Planning across } \\
\text { Multiple Domains Supported } \\
\text { by RFID Devices }\end{array}$ & iSURF & Completed & $\begin{array}{l}\text { http://www.srd } \\
\text { c.com.tr/isurf/ }\end{array}$ & $\begin{array}{l}\text { iSurf: } \\
\text { http://sourceforge.net/projects/isur } \\
f\end{array}$ \\
\hline $\begin{array}{l}\text { Interactive Knowledge Stack } \\
\text { for small to medium } \\
\text { CMS/KMS providers }\end{array}$ & IKS & $\begin{array}{l}\text { Under } \\
\text { developme } \\
\text { nt (to be } \\
\text { completed } \\
\text { December } \\
\text { 2012) }\end{array}$ & $\begin{array}{l}\text { http://www.iks- } \\
\text { project.eu/ }\end{array}$ & \\
\hline Knowledge in a Wiki & KiWi & $\begin{array}{l}\text { Under } \\
\text { developme } \\
\text { nt (to be } \\
\text { completed } \\
\text { February } \\
\text { 2011) }\end{array}$ & $\begin{array}{l}\text { http://www.kiwi } \\
\text {-project.eu/ }\end{array}$ & http://kenai.com/projects/kiwi/ \\
\hline $\begin{array}{l}\text { An Open Source Environment } \\
\text { to construct Information } \\
\text { Services for Children }\end{array}$ & PuppyIR & $\begin{array}{l}\text { Under } \\
\text { developme } \\
\text { nt (to be } \\
\text { completed } \\
\text { April 2012) }\end{array}$ & $\begin{array}{l}\text { http://www.pup } \\
\text { pyir.eu }\end{array}$ & \\
\hline $\begin{array}{l}\text { Identity-Based Tracking and } \\
\text { Web-Services for SMEs }\end{array}$ & TRASER & completed & $\begin{array}{l}\text { http://www.tras } \\
\text { er-project.eu }\end{array}$ & $\begin{array}{l}\text { http://sourceforge.net/projects/tras } \\
\text { er/ }\end{array}$ \\
\hline Wireless Sensor Network & WISENET & completed & $\begin{array}{l}\text { http://cegt201. } \\
\text { bradley.edu/pr } \\
\text { ojects/proj200 } \\
\text { 3/wisenet/ }\end{array}$ & $\begin{array}{l}\text { http://cegt201.bradley.edu/project } \\
\text { s/proj2003/wisenet/ }\end{array}$ \\
\hline $\begin{array}{l}\text { Advanced predictive-analysis- } \\
\text { based decision-support } \\
\text { engine for logistics }\end{array}$ & ADVANCE & $\begin{array}{l}1 \text { Sept } \\
2010-\text { end } \\
\text { Aug } 2013\end{array}$ & $\begin{array}{l}\text { http://www.adv } \\
\text { ance- } \\
\text { logistics.eu/ }\end{array}$ & $\begin{array}{l}\text { http://sourceforge.net/projects/adv } \\
\text { ance-project// }\end{array}$ \\
\hline
\end{tabular}

Table 1: EU-funded OSC-based projects

Various web-based source code repositories exist from which consortia can choose for hosting their developments. Some of the most popular ones are: SourceForge, Alioth, RubyForge, CodePlex, Tigris.org, BountySource, CVSDude, GNU Savannah, BerliOS, JavaForge. A comparison of open-source software hosting facilities can be found at http://en.wikipedia.org/wiki/Comparison_of_open_source_software_hosting_facilities.

The type of license applicable to the source code uploaded to these sites is typically constrained, but the choice is up to the authors. Two commonly used licenses are the GNU LGPL and the Apache license which are popular because they permit the use of the software in proprietary/commercial products.

Typical type of information sources made freely available by project consortia are:

- software,

- user manuals and other software related documents,

- scenario descriptions,

- scientific publications,

- deliverables,

- multimedia material,

- concise information material (e.g., flyers).

Another aspect of the OSC projects is represented by those that make use of free and opensource software in their own developments, seeking to improve the technologies used and to remove barriers to their adoption (16). Some of the initiatives supported by the European Commission are highlighted in Table 2. 


\begin{tabular}{|l|l|l|}
\hline \multicolumn{1}{|c|}{ Project title } & \multicolumn{1}{|c|}{ Acronym } & \multicolumn{1}{c|}{ Web-page } \\
\hline $\begin{array}{l}\text { Environment for the development and } \\
\text { Distribution of Open Source software }\end{array}$ & EDOS & http://www.edos-project.org \\
\hline $\begin{array}{l}\text { Free/Libre/Open Source Software: } \\
\text { International Cooperation development } \\
\text { roadmap }\end{array}$ & FLOSSInclude & http://www.FLOSSinclude.org/ \\
\hline $\begin{array}{l}\text { Free/Libre/Open Source Metrics and } \\
\text { Benchmarking }\end{array}$ & FLOSSMETRICS & http://FLOSSmetrics.org \\
\hline $\begin{array}{l}\text { Free/Libre/Open Source Software: } \\
\text { Worldwide impact study }\end{array}$ & FLOSSWORLD & http://FLOSSworld.org \\
\hline $\begin{array}{l}\text { Free/Libre/Open Source Software: } \\
\text { Policy Support }\end{array}$ & FLOSS-POLS & http://www.flosspols.org/ \\
\hline $\begin{array}{l}\text { Managing the Complexity of the } \\
\text { Open Source Infrastructure }\end{array}$ & MANCOOSI & http://www.mancoosi.org/ \\
\hline $\begin{array}{l}\text { Open-Source API and Platform for } \\
\text { Multiple Clouds }\end{array}$ & mOSAIC & www.mosaic-project.eu \\
\hline $\begin{array}{l}\text { Implementing Python in Python } \\
\text { Quality Platform for Open Source } \\
\text { Software }\end{array}$ & PyPy & $\begin{array}{l}\text { http://codespeak.net/pypy/dist/pyp } \\
\text { y/doc/home.html }\end{array}$ \\
\hline QUALity in Open Source Software & QualiPSo & http://www.qualipso.org/ \\
\hline $\begin{array}{l}\text { Software Quality Observatory for Open } \\
\text { Source Software }\end{array}$ & SQO-OSS & http://www.qualoss.org/ \\
\hline $\begin{array}{l}\text { Building and Promoting a Linux-Based } \\
\text { Operating System to Support Virtual } \\
\text { Organizations for Next Generation Grids }\end{array}$ & XtreemOS & http://www.xtreemos.eu/ \\
\hline
\end{tabular}

Table 2: EU supported OSC related projects

\section{PROJECT EXAMPLE: TRASER}

One of the open-source projects that can serve as a learning/teaching base is the TraSer project (http://www.TraSer-project.eu). TraSer has been completed in May 2009, had a period of development of 3 years and was funded partly by the European Union under the $6^{\text {th }}$ Framework Programme, partly by the companies involved in the consortium.

The primary goal of the project was the development of a free, open-source software package offering affordable item-centric tracking and tracing solutions for small and mediumsize enterprises (SMEs) operating in environments transcending company or organizational borders. A special release of the solution platform was adapted to tracking product data files (e.g., blueprints produced by several industrial partners during collaborative product design). Data tracking has particular relevance as today, company assets more and more dominantly exist as electronic data that have to be consistently guided through their intended life cycle and protected from unauthorized access.

The software outcomes (and related documents) of the project have been made freely available to the open-source community on SourceForge under a GNU LGPL license.

\subsection{Project overview}

The project responded to recent trends in industrial production which are marked by increased demands regarding observability of manufacturing and delivery processes. Tracking (i.e., keeping track of selected properties of a unique entity) and tracing (i.e., keeping track of the interactions of a given entity with other entities, chiefly regarding events in the past) are regarded as suitable means of achieving the aforementioned transparency. In some cases, such as the food industry, a certain degree of traceability is already made mandatory by law, while numerous other branches have also experienced the benefits of transparency, especially if seamless integration across corporate borders is made possible. 
The TraSer solution platform, main output of the TraSer project, is an open-source framework that enables the establishment of such track-and-trace networks by offering support for tracking and tracing on the level of items with unique identity (as opposed to the purely quantitative, account-based view of stock levels, item count, etc.).

The primary advantage of performing tracking on the level of items or batches (instances, in general; as opposed to class cardinality with account-based operations) is that the path or the presence of material can be tracked with higher accuracy than that of conventional structures. As a consequence of aggregation over all locations involved, detailed materialrelated information can be acquired and processed more efficiently, which in turn facilitates better decisions in material management and related issues, ranging from more efficient logistics in supply-chain management to optimized usage of material in asset management (14).

The TraSer project had the following main technological and scientific objectives:

- Assessing possibilities of integrating item-centric concepts into an existing transaction-processing scheme;

- Providing scalable and flexible access control while complying with industrial security requirements;

- Exploring and applying best practices for realizing network-level services in heterogeneous and changing environments.

- Seeking possible ways of motivating prospective partners to participate in networkwide information sharing (such as through scientifically founded guarantees for safe and efficient operation);

- Gathering commercially exploitable "best practices" and technological solutions which can facilitate the composition and gradual improvement of network-level services. Figure 1: Account-based material
management
Figure 2: Item-centric material management

The most fundamental requirement to be met before establishing tracking is the agreement upon a common identification system, consisting of:

- $\quad$ one or more standard types of physical ID carrier, and

- one or more ID allocation scheme which all users can interpret.

In order to allow the use of cheapest technologies, TraSer merely requires a unique identifier to be stored on the tag-which is already granted by passive tags or even bar codes or any other means of identification which can store an identifier of the necessary length, possibly not more than 64 bytes. While it is possible to store further data and integrate further functionalities with more sophisticated RFID tags, TraSer assumes that item-related data are, primarily, not stored directly on the tag but in a database which can be reached through the corresponding TraSer node, i.e., using a network connection. This way, the cooperating partners are able to share item-related information with each other. 
TraSer uses an internal identifier notation (ID@URI) where each unique ID already contains the address of the access point for the related services, thus eliminating the need for a comprehensive lookup service and allowing a decentralized allocation of identifiers (see also Figure 3). While this principle does have some drawbacks (e.g., those related to change of ownership and transfer of data maintenance responsibilities), it offers key advantages that make it attractive for small-scale users and occasional participants. In its implementation in TraSer, the ID@URI scheme relies on the-already granted-uniqueness and resolvability of domain names via the DNS mechanism for the URI part of the unique identifier, whereafter the owner of a given URI only has to grant the local uniqueness of its own ID entries in the ID@URI string to ensure global uniqueness. This implies that global uniqueness and resolution of service access addresses are given without allegiance to a central identifier provider which certainly is an attractive choice for entry-level users, occasional participants or experimenting students.

Another advantage for low-budget users of TraSer is that it does, generally, not require the use of a specific tag type: any physical ID carriers (e.g. barcode, RFID) can be used that can either accommodate the ID notation internally used by TraSer, or are in a numbering scheme that can be mapped onto TraSer's internal notation by the clients deployed in the given application. This is one of the features that make it easy to adapt TraSer to other tracking networks.

Figure 4: Comparison of lookup-based mapping of unique ID and service access address (a) vs. the ID@URI principle (b) where the access address for services related to the given item can directly be obtained from the unique ID.

TraSer relies on web services for communication-a widely acknowledged set of standards with a large spectrum of implementations available, both open-source and proprietary. This reliance on well-known standards also allows users to easily implement their own components that can be integrated into their targeted TraSer network.

A TraSer network (note that there is no such thing as the TraSer network-many independent communities can exist at a time) consists of TraSer servers and TraSer clients, each type of node having clearly separated, specific roles in the network. Item-related data are maintained by TraSer servers which communicate with each other if queries or updates are forwarded or broken down to distributed components. TraSer servers respond to queries and item-related updates in XQuery, a query language that allows returned content to be hierarchically structured in an XML tree (as opposed to "flat" results of, e.g., SQL queries), which is facilitating an easy adaptation to varying product data models and description of composite products (it is enough to think of customized computers with varying subassemblies, or automobiles produced in a "customize-to-order" scheme). The typical point where access control decisions are taken is, again, the TraSer server (note that in an open network, queries can arrive from any client) - current possibilities include several levels of granularity from member-by-member to item-by-item, but access control rules can also be implemented. Updates communicated to TraSer servers are regarded as events that have effect on the values of certain attributes of a given unique item. In case an item contains sub- 
Figure 5: Access to item-related services in a TraSer network using various methods of unique identification and specialized clients using different interfaces. Freedom in addition of customized clients allows the adaptation and coupling of a TraSer-based solution with other components and systems

TraSer clients serve as interfaces "to the rest of the world", including human operators, automated checkpoints or other components of the given IT infrastructure (see also Figure 5). Entering data into the system is always performed by TraSer clients, however, their layout depends on the specifics of the given application. Since the atomic updates of the TraSer servers are on the level of discrete events, one of the key factors determining the layout of the clients is the form in which event-related (possibly raw) information is fed into the clients from the environment (which can be readers, operators, other IT components etc.). Where RFID readings are involved, the clients either communicate directly with the readers through a high-level interface, or are coupled to dedicated middleware that generated discrete events based on series of raw RFID readings. It is also possible to operate clients without constant connection to the servers (such as uploading recorded events at the end of a shift), however, this has only been implemented with mobile clients processing bar codes. (An overview of major classes of RFID tags and readers, commonly used frequencies and identifier systems, current and envisaged fields of application, as well as advantages, concerns and limitations of use can be found in (15)).

Useful functionalities for handling item-centric data as advanced search and aggregation support, views at historical data, or backtracking of information have been implemented. These facilitate special actions, such as focused recall campaigns or locating of certain goods in the production chain, which are, nowadays, still seriously hampered in heterogeneous production networks due to the lack of transparency and commonly accepted interfaces.

Flexible definition of data models is allowed and facilitated by XQuery-based interfaces, which is of special importance for enterprises of high product variability Furthermore, users can easily extend or overlay existing product data maintained by other manufacturers which adds further flexibility and freedom in data model planning.

Ten pilots of different magnitude and practical relevance were conducted during the project development phase. Half of the pilots were using RFID. The usage scenarios ranged from closed-circuit tracking of re-usable equipment to tracking of goods in a supply chain across multiple collaborating partners. While some of the pilots were confined to a research environment, others targeted logistics, healthcare, food industry, and different branches of 
product design and manufacturing (e.g., automotive electrical components). Geographically, the pilots have been conducted in Finland, Romania, the Netherlands and Hungary.

\subsection{Learning with TraSer}

A wide spectrum of learners can benefit from the TraSer platform, ranging from students studying, e.g., engineering, logistics, supply chains, management, informatics, health care. Also, industrial employees can benefit, even by being presented with simplified demonstration tools of their-usually much more complex-real-life industrial processes. Nowadays, engineering and technical education or vocational training have numerous focal areas where track-and-trace solution platformns like TraSer can facilitate the learning process and can give additional insight into the nature of the examined problem domains. The most typical of these are:

- Product development-Collaboration in product design and prototyping has gained much importance in recent decades, and this is also evidenced by changes in education, placing a growing emphasis on collaborative processes and interdependencies in design decisions. Since distributed product design is, by now, frequently practiced in the industry, students preparing for their professional work are well-served by demonstration environments that are not only able to simulate or track such interlinked patterns of engineering decisions but also grant a deeper look beind the facades to explore implications and constraints that would otherwise remain hidden in real life.

- Manufacturing systems and manufacturing processes-Here, in-depth observability of the system and its processes can be provided, so that students can examine and recognize events and interdependencies that would otherwise be hidden or difficult to demonstrate. This can play a key role, e.g., in understanding system layout and scheduling problems. Aside from serving as a "probing tool", a track-and-trace platform can be an active part of the manufacturing system itself: integrated into simulations or real-life models, TraSer can provide a testing environment to assess the impact of process transparency, proper choice of data models or the effect of data errors and disruptions that can be introduced on purpose in an experimental system.

- Equipment maintenance-Track-and-trace solutions are, nowadays, often becoming an essential part of equipment surveillance and maintenance, not only within manufacturing processes. A track-and-trace platform can enhance a student's insight into processes and phenomena that play a major role in scheduling and execution of maintenance and repairs but require a comprehensive overview over an entire pool of equipment or over a longer period of operation. Using a track-and-trace system, even the usage of physical demonstration equipment can be enriched by operation-related information resources regarding equipment wear, failure events, equipment life-time and reliability, etc.

- System design-Many fields of engineering education experience the growing emphasis of system design, as a response to real-life solutions becoming more and more complex. An experimental environment where architecture, component behavior and communication can be observed "from the ground up" and an entire system can be assessed as a whole at the same time, gives students a good opportunity to examine system design decisions-in our case, primarily data model, allocation of resources and network nodes, system reliability, or access restriction decisions.

The progress of learning can be greatly enriched by the TraSer solution platform, as it presents an affordable environment for gaining hands-on experience with numerous aspects of automatic identification and track-and-trace. In this context, an important advantage of TraSer is that it is entirely open-source and allows students to gain practical experience with system development and integration with other components that can be encountered in a 


\section{Assessment in an educational context}

In order to assess the applicabiliy of a given solution framework for educational purposes, the following main aspects have to be examined:

- What topics of education can be directly served by the system itself? In case of TraSer, the answer is straightforward and was already presented in detail in the previous subsection.

- What are the education areas that could benefit from an embedded use of the framework? While embedded or combined use (as in (18)) certainly requires more efforts in preparation, it may very well introduce indirect benefits. For TraSer, areas of potential application-related benefits were outlined in the previous subsection. Note that it is difficult to give a general scheme of evaluation, and the steps of gathering required/preferred functionalities and assessment of the framework's contribution to these is largely determined by the charateristics of the given application.

- How much and what supplementary material is available? While this aspect is closely related to the previous issues regarding application domains, it may deserve to be handled separately, since proper preparation of course material usually comprises a considerable part of an instructor's efforts. As already addressed in the previous subsection, TraSer is well-supplemented with explanatory material which, due to the estimated low level of expertise of the targeted user range, already has the character 
of educational material. Nevertheless, domains requiring embedded use of the platform are still in need of developing suitable supplementary materials.

- How much additional insight does the framework provide? In general, education is required to provide deeper insight than what could be gained by a real-life industrial example (i.e., more transparency, flexible choice of process time scales and the possibility of recordig, aggregation or other enhanced analytical views of data otherwise rarely used in real life). This aspect should always be kept in mind while assessing frameworks for educational use. Although it was not meant to provide a full spectrum of these functionalities, the TraSer framework does provide temporal aggregation and directed search functionalities beneficial for the aforementioned purposes, and owing to its open-source character, additional functionalities of this kind could be just as easily implemented.

The TraSer solution package was not directly meant to be an education aid, and to date, hands-on use with university students is only in its preparation phase. Nevertheless, experience showed that a major part of the activities exerted with prospective users is actually education at various levels of expertise. It was found that the understanding of prospective users is much facilitated by presenting the functioning of the solution platform in an industry-related sample implementation that is close to their given field of usage.

\section{An example: embedded use in production system simulation}

As an example illustrating the embedded presentation of a TraSer-based solution, we show here a demo application of the TraSer platform in combination with simulated processes built using eM-Plant, a commercially available environment for simulating production plants. In our case, tracking information did not influence production decisions, therefore, simulation and tracking tests could be decoupled, and the TraSer system could be fed with data generated off-line. While this can greatly contribute to the repeatability of experiments, it is important to emphasize that the web service interfaces of TraSer do very well allow real-time operation coupled with other, possibly asynchronously running, systems.

The demo application shown here presented a simplified model from the food industry, allowing several important aspects to be examined:

- registering of repeated quality check results and detection of earlier errors,

- assembly-like processes where previously disjoint entities are assigned to a commonly occupied container or super-assembly either permanently or for a limited duration,

- disassembly-like processes where a given entity is decomposed to sub-items which obtain their own unique identities while retaining reference to the original item if needed,

- automatic propagation of changes that affect a group of items in physical reality.

A simplified scenario served as a basis for the demonstration where, for the sake of simplicity, some typical constraints of the food industry (e.g., spatial separation of processing paths) were omitted. Figure 6 depicts the schematic food supply chain modeled in the tracking application, containing:

- three producers of eggs, cattle and broccoli, respectively,

- one plant processing the raw products (see also Figure 7),

- a network of shops selling the products, and

- appropriate logistics services with separate routes.

The egg producer delivers eggs as separate items. In the processing plant, these are combined to boxes, each containing the same number of individual eggs. During this process, the box combining individual items appears as a super-assembly, and receives its own new unique identity.

The cattle farm delivers cattle to the processing plant where the meat of the animals is packed in cans that appear as new unique items. In order to ensure that a given product can 
be traced back to the originating cattle (note that the need for such measures is recently gaining increasing attention in the meat industry), links from cans to cattle entities are established and remain intact after processing.

Broccoli is received from the grower and then checked for quality, to end up either as "human-consumable" or "feed-quality" vegetable. While only vegetable classified as humanconsumable is being delivered to the shops, one more local check is performed that may override previous predicates. In our demo case, false decisions were introduced into the simulation on purpose, in order to examine how detection of human error is handled by the tracking system.

Ambient conditions during transportation can affect the quality of the products being delivered-this holds all the more for food supply chains. In addition to installing appropriate appliances for keeping transportation conditions (e.g., temperature, humidity) within tolerances, the conditions are more and more often regularly checked and reported both as a credential measure for guaranteed quality, as well as for limiting responsibility in case of quality complaints. Transparent reporting is demonstrated in our example by simulated temperature readings unique to each vehicle taking part in the logistics processes. Simulated measurement occurs in certain time intervals and the values are registered in the history of the given vehicle. Since the goods transported in the vehicle are logically linked to the observed transportation asset, the values of temperature readings can be automatically forwarded to the corresponding attributes of the transported products where they permanently remain to allow subsequent quality checks and tracing of an item's history.

The TraSer-based demo application not only performs the tracking operations themselves: being part of the TraSer package by default, versatile TraSer clients are at the user's disposal that, again, provide valuable support for education by suggestive visualization of recorded data and comprehensive search functionalities. TraSer clients also support the export of selected data, e.g., to serve as a starting point for statistical analysis in planning directed recall actions or pinpointing potential system bottle-necks.

Figure 6: Processes inside a sample food processing plant 


\section{CONCLUSIONS}

Today's situation of economy and industry requires the skills and technical knowledge of the employees to be practice-oriented and flexible, capable of independently exploring and adopting new perspectives and solutions in a life-long learning process. The paper pointed out that the proper attitude of education can effect considerable improvement in this domain, and much has to be changed in today's education itself to further facilitate this progress, especially in response to the growing complexity of technical systems where the recognition or awareness of interdependencies is of increasing importance.

The paper proposed open-source software and open-source communities as one of recent achievements that can support these changes in education, since open-source software can help learners look beyond a "black box" perspective and gain better understanding of a solution's inner functioning, especially regarding phenomena that are usually hidden in reallife industrial environments. Open-source also means that modifications or extensions can easily be added and the results can be tried directly in practice without such burdens as approval by or allegiance to a central provider, allowing learners to gain hands-on experience in their knowledge domain with as little overhead as possible. The paper listed fundamental aspects of applicability in an educational field-according to these, assessment has to take direct and embedded applicability, as well as readily available literature and additional, didactically valuable, perspectives in consideration.

The paper presented the TraSer project and its open-source solution platform in detail, underlining its suitability for education by listing further highlights of the project's output (e.g., industrial surveys and white papers) that can serve as valuable information sources for learners. Although TraSer has not yet been directly applied for education (e.g., university courses), the paper has shown that TraSer is well-aligned with the assessment criteria for potential educational support. Aside from ongoing preparations regarding educational use, the TraSer platform and its accompanying materials have already shown education-related advantages during staff training carried out in preparation of pilot applications. 


\section{REFERENCES}

(1) EU, 2009: Draft Triennial Work Programme, http://eit.europa.eu/press/newsarchive/single-view/article/first-eit-draft-triennial-work-programme-is-sent-to-thecouncil-the-europeanparliament-and-the-eur.html, accessed 4.08.2009.

(2) Ilie-Zudor, E., Kemeny, Zs., 2006: eSCM - An Interactive Education and Discussion Platform for Supply Chain Management (http://www.ercim.org/publication/Ercim_News/enw65/ilie-zudor.html, ERCIM News, No. 65, April, pp. 37-38.

(3) Arndt T., Chang S.K., Guercio A., Maresca P., 2007: An XML-Based Approach to Multimedia Software Engineering for Distance Learning, in Future Directions in Distance Learning and Communication Technologies (Advances in Distance Education Technologies - vol 1) edited by Timothy Shih and Jason Hung, Idea Group Inc., pp. 106-134.

(4) Curtis, D.D., Lawson, M.J., 2001: Exploring collaborative on-line learning, JALN Volume 5, Issue 1 - February 2001.

(5) Chien Chou, Hsieh-Lung Hsu, Yu-Seng Yao, 1997: Construction of a virtual reality learning environment for teaching structural analysis, Computer Applications in Engineering Education, Volume 5, Issue 4, pp. 223-230.

(6) Sheng-Jen (Tony) Hsieh, Patricia Yee Hsieh, 2005: Web-based modules for programmable logic controller education, Computer Applications in Engineering Education, Volume 13, Issue 4, pp. 266-279.

(7) Balamuralithara B., Woods P. C., 2008: Virtual laboratories in engineering education: The simulation lab and remote lab, Computer Applications in Engineering Education Journal, vol. 17/1, DOI: 10.1002/cae.20186.

(8) Iskander M. F., Catten J. C., Jameson R. M., Rodriguez-Balcells A., Jones A. K., 1996: Interactive multimedia CD-ROMs for education, Computer Applications in Engineering Education Journal, vol. 4/1, pp. 51-60.

(9) Sanz S., Iskander M. F., Yu L., 2000: Development of an interactive multimedia module on antenna theory and design, Computer Applications in Engineering Education Journal, vol. 8/1, pp. 11-17.

(10) Aminmansour A., 1996: Utilizing the best of today's technologies to better educate engineers of tomorrow, Computer Applications in Engineering Education Journal, vol. 4/1, pp. 79-84.

(11) See A., 2006: Challenging computer-based projects for a Mechatronics course: Teaching and learning through projects employing virtual instrumentation, Computer Applications in Engineering Education Journal, vol. 14/3, pp. 222-242.

(12) Al-Nuaimy W., Zhang J., Noble A., 2001: Web-based learning environment for a communications module, Computer Applications in Engineering Education Journal, vol. 9/2, pp. 114-121.

(13) Seffah A., Desmarais M., Khuwaja R., 1999: Mastering object-oriented technology using a self-learning and self-assessment system, Computer Applications in Engineering Education Journal, vol. 7/3, pp. 162-170.

(14) Ilie-Zudor E., Szathmári M., Kemény Zs., Karnok D., Monostori L., 2008: Identitybased, item-centric tracking platform for logistics applications, The International Workshop on Harbour, Maritime \& Multimodal Logistics Modelling and Simulation (HMS2008), September 17-19, Campora San Giovanni, Italy, ISBN: 978-88-903724-21, pp. 10-19.

(15) Ilie-Zudor E., Kemény Zs., Egri P., Monostori L., 2006: The RFID technology and its current applications, The Modern Information Technology in the Innovation Processes of the Industrial Enterprises MITIP 2006, ISBN 963865865 7, pp. 29-36.

(16) Software \& Service Architectures and Infrastructures, Free and open source software activities in European Information Society initiatives, http://cordis.europa.eu/softwareservices. 
(17) Jaccheri, L., Osterlie, T., 2007: Open Source Software: A Source of Possibilities for Software Engineering Education and Empirical Software Engineering. In: Proc. of the First International Workshop on Emerging Trends in FLOSS Research and Development (FLOSS'07: ICSE Workshops 2007), Minneapolis, MN, May 20-26, 2007, DOI 10.1109/FLOSS.2007.12

(18) Meza, C., Andrade-Romero, J.A., Bucher, R., Balemi, S. 2009: Free open source software in control engineering education: A case study in the analysis and control design of a rotary inverted pendulum. In: Proc. of the $14^{\text {th }}$ International Conference on Emerging Technologies \& Factory Automation, ETFA 2009. pp. 1-8, DOI 10.1109/ETFA.2009.5347162

(19) Vanfretti, L; Milano, F, 2010: Experience with PSAT (Power System Analysis Toolbox) as free and open-source software for power system education and research. International Journal of Electrical Engineering Education, vol. 47/1, pp. 47-62

(20) Nandigam, J.; Gudivada, V.N.; Hamou-Lhadj, A., 2008: Learning software engineering principles using open source software. In: Proc. of the $38^{\text {th }}$ Annual Frontiers in Education Conference, FIE 2008, pp. S3H 18-23. DOI: 10.1109/FIE.2008.4720643 